\title{
Probe on Myth and Hero, A Case Study of Harry Potter: Asserting Harry Potter as a Modern Mythical Hero
}

\author{
Devu M Suresh \\ Assistant Professor \\ Assumption College Autonomous \\ Changanacherry, Kerala, India \\ devumsuresh152@gmail.com
}

\begin{abstract}
A Hero is the one who stands unique as his own, based on the presumption that, he is someone who has given his or her life to something bigger than oneself. Throughout this research paper, there have been undertaken many references and probes to the realm of 'Hero', obviously that of 'Mythical Hero', as the ideology concerning hero dates back it's root in ancient myths and legends all over the world. Myriads of attempts have been made to the 'Hero Myth Cycle' proposed by Campbell, to assert the novel conception, concerning the well renowned fictional character, Harry Potter as a 'Modern Mythical Hero'.
\end{abstract}

Keywords: Myth, Mythical Hero, Fantasy, Magic, Archetype

Harry Potter saga is being compartmentalised as a unique piece of children's fantasy book, and a milestone in the history of modern literature, as it is the one which admiringly conquered the minds of millions and millions of readers all around the world serving the uncanny world of 'magic'. One splendid credit it has of its own for ever in the arena of literature is that, unlike other fantasy works, instead of satisfying merely the realm of 
entertainment, it has transcended to the degree of many critical readings, analysis and even researches.

Children are understandably intoxicated with the kind of power that Harry along with his companions Ron, Hermione and others in his world possess. Rowling once agreed that the idea that we could have a child who escape from the confines of the adult world and goes somewhere where he has power, both literally and metaphorically, really appealed to her. When the first sequel of the Harry Potter saga, Philosopher's Stonewas published in Britain, it was a great victory beyond words. The saga narrates the heroic and adventures journey of the title character Harry, who is destined to slay the evil wizard, Lord Voldemort, who killed his parents and committed series of other bizarre deeds. The saga comprises of seven massive series published one after the other. Its focus is keenly on the plights of young Harry, who is selected to partake the prestigious 1000-year- old-Hogwarts school of witchcraft and wizardry. Harry himself is an orphan, his parents(practitioners of white magic) was mercilessly assassinated by the dark wizard, Lord Voldemort! But when Lord Voldemort, the most powerful evil wizard for a century turned the killing curse ('AvadaKadavra'), which had killed so many witches and wizards, on Harry and soon it rebounded upon Voldemort, ripping him from his body, and his powers vanished, barely alive, he fled in asylum. Young Harry is given an uncanny 'marking' on his forehead resulted out of his first death-defying encounter with Voldemort!

Little is said during the time Harry's parents are slaughtered until he is around 10 years old. When he turns to the age of 11, Harry is given an 'invitation' to the magical world, 'Hogwarts', where he was trained to be the paragon of wizard with proper guidance by a number of professors, who proved their calibre in the arena of magic! And after a long gap, withstanding myriads of breath-taking and death-defying episodes of trials and fights, Harry efface the 'evil dark lord', Voldemort and thereby rescued the lives of his fellowmen. 
In order to investigate and to sustain the ideology concerning 'Mythical Hero', this research paper relies on the theory of 'Myth' and also the theory of 'Archetypes'. The very term Myth invokes thoughts and images that line up with make-believe, stories of gods, fairy tales, or tales of heroes. Myths, whatsoever, deserves incredible significance and belongs as such to every culture, and making 'myth' synonymous with untrue story is an awful and unfortunate development of rationalism!

Each culture and civilizations brings up and nurture myths of their own and maintain them as part of their origin and evolution. The well-known American Mythologist Joseph Campbell once opined that myth is what we call other people's religion. The term 'myth' has its evolution from the Greek word "Mythos", meaning story. But, if we attempt a close reading, it could be trace out that myth is not just a mere story and is more elevated than even history, rather it is something more reliable and true than them!

Northrop Frye, the famous Canadian literary critic, once commemorated in his Anatomy of Criticism, that 'not one genre but all genres of literature derive from myth, especially, The Myth of the Life of the Hero'. Frye annexed myth and literature so closely together, even without collapsing literature in to myth, his literary criticism is confusingly called Myth Criticism. Equally commonly, his literary criticism is termed as Archetypal Criticism. Because, in simply calling the genres of literature 'Archetype', he is misinterpreted for a 'Jungian' and, again, the grandest of practitioners.

Jung depended on the Greek term 'Archetype' to define these contents. Our psychic archetypes are recurring patterns of symbols, images and stories that assist one to make sense of our lives. Further studies proved that, we are capable to reveal essential archetypes and symbols in dreams and myths. While dreams are individual manifestations of the one's own unconscious, myths on the other hand, are said to have societal manifestations of the 
collective unconscious. In literature, we can often assume and identify archetypal geographies like a Garden of Eden, or a hellish wasteland. And character types like heroes and villain. Also, story aspects like journeys or monster slaying and themes like good versus evil.The relationship between myth and literature has taken varying forms. The most obvious form has been the use of myth in works of literature. The central myth of literature is the 'Quest Myth'.

In Anatomy of Criticism, famed Canadian literary critic Northrop Frye asserted that not one genre but all genres of literature derive from myth-especially, 'The myth of the life of the hero'. Frye assimilates the life cycle of the hero with several other cycles: the cycle of the sun, the yearly cycle of the seasons, and the nighty cycle of dreaming and awakening. Both Frazer and Jung intended to be accounting for the origin and the function, not simply the meaning, of myth, and the grammars they allow are intended as proofs, not as compendia of symbols. Frazer argues that ritualistic regicide did occur in reality, even if it later got watered down to mere drama. Jung claims that archetypes really exist in the conscious mind and even in the world.

'Archetypal Criticism' is a critical approach to literature. It is also a critical theory that interprets a text by focussing on recurring myths and archetypes in the narrative, images, symbols, and character in works of literature. As a form of literary criticism, it dates back to 1934 when Maud Bodkin published Archetypal Patterns in Poetry. Archetypes are universal symbols that appears in literature, myth, dreams, oral traditions, songs etc. They are generally considered 'Primordial Images' or the 'Psychic Residue' of repeated types of experience in the lives of very ancient ancestors which are inherited in the 'Collective Unconscious' of the human race and are expressed in myths, religion, dreams, and private fantasies, as well as in the works of literature. Some common examples are, the child, the hero, the great mother, the wise old man, the trickster or fox etc. 
Campbell, one of the greatest archetypal critic, made serious probe in studying mythical stories across the world since the evolution of man and discovered they all had twelve common features. And this has come to be known as the 'Hero's Journey', and these features are at play in almost every legendary stories ever told since Odysseus.

Following many challenges, and tasks, it is quite astonishing, how Harry potter tend to be accepted as an 'Archetypal or mythical hero'. So, as it is interesting and informative, in finding and asserting the fact that, Harry potter is a Mythical hero, lets eye more on the Heroic Journey, the popular ideology moulded by Campbell in his pioneering work, The Hero with a Thousand Faces. Campbell once asserted in it, the normal process of Heroic Journey, "A hero ventures forth from the world of common day in to a region of supernatural wonders: Fabulous forces are there encountered a decisive victory is won; the hero comes back this mysterious adventure with the power to bestow his fellow man" (Campbell 30).

"A true Hero isn't measured by the size of his strength, but by the strength of his heart", these very words of Hercules provides lights to the heroic and adventures life journey of Harry potter. Campbell's "Hero Myth Cycle" stands testimony to this very notion of Harry potter. The following diagram narrates Campbell's "Hero Myth Cycle". 


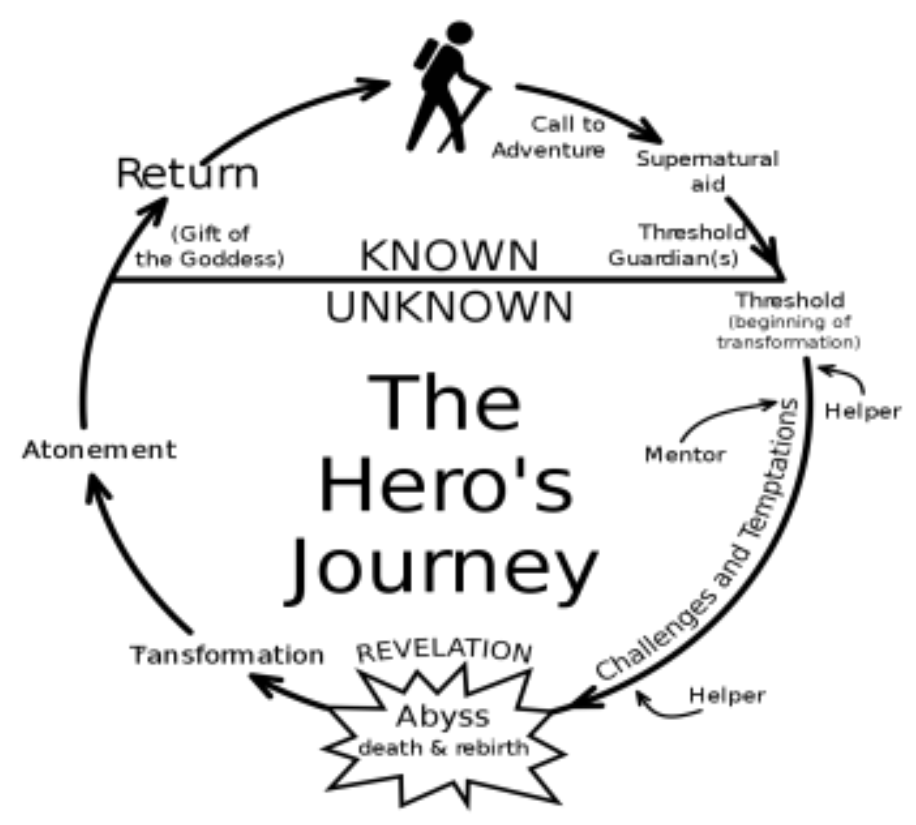

According to Campbell, myths serves guidance, teaching young people about their own life and provides perfect life models. However, 'The models must be appropriate to the time in which they are living' (Campbell 13), that is to say, the models should 'be up to date', a modernised version to match today's life of young people. In this modern IT world, where everything takes place 'at the click of a button', it is not that easy to enchant children's attention, who want action. The Harry Potter sequences fulfil this need by satisfying action and supernatural episodes.

Campbell's notion of 'The Mono Myth' offers a recognisable pattern to the heroic story. Campbell's theory is that, 'there is one myth with, a hero with a thousand faces'. The story follows a three step realms of 'Separation, initiation, and return' that can be later broken down in to seventeen specific stages. Campbell attempted a wonderful description of the 'hero myth pattern' that each hero follows. A hero ventures forth from the world of the common day into a region of supernatural wonder, fabulous forces are encountered and a decisive victory is won, the hero comes back from this mysterious adventure with the power to bestow boons on his fellow man. The motto of the mythical quest is the one that has been written about for generations. The tale of the hero satisfies the reader a sense of hope. The 
plot of Harry Potter revolves around the popular theme of good versus evil. According to Campbell, the first portion of the heroic journey begins with the 'departure'. This so called 'departure' is further broken down into five parts. The first and the most important of the five parts is termed as 'Call to adventure', followed by the 'Refusal of call'. This beginning is quite typical as the hero is called to duty and then seeing himself or herself as an ordinary person, denies they could perform the task.

In Chapter 3 of Philosopher's Stone, we are introduced to letters falling down on and around Privet Drive, signifying Campbell's second stage of the 'Hero Myth Cycle', 'Call to adventure'. "Three things lay on the doormat: a postcard from uncle Vernon's sister Marge, who was vacationing on the Isle of Wight, a brown envelope that looked like a bill, and "A letter for Harry" (Philosopher's Stone 34). The third stage, Refusal to the Call gets a little funky here, as Harry himself doesn't actually refuse it. In fact, it's the Dursley's, who refuse it. They go to absurd lengths to stop the letters from coming. But still, they haven't succeed it as Hagrid enters in the Fourth chapter of Philosopher's Stone. And he claims for Harry and thus, acting the role as 'Mentor' in the 'Cycle'. The next prominent 'Mentor', who satisfied its very notion is Albus Dumbledore. Along with it he also fulfilled the role of 'The Wise Old Man' of the Cycle.

In the case of Harry Potter and the Philosopher's Stone the Heroes Journey is in fact divided in to two; the one through 'Normal world' and the other through 'The unknown', according to Campbell's notion of 'Hero Myth Cycle'. At the start, Harry was unknown of his past and even present who he was? His parents? Who actually he at present? He is at Dursley's family.

In the following step of Campbell's Hero Myth Cycle points to 'trials, failures, tests, allies and enemies'. When analysing Hogwarts based on these points in mind, it is evident 
that Hogwarts ain't exactly safe. It has got Trolls in the bathrooms, three- headed dogs in the basement and magic mirrors that will swallow your soul. Most significant among them is the three-headed dog 'Fluffy'. One can find out a similar looking prototype of the 'three-headed dog', Fluffy in Greek mythology. In ancient Greek mythology, there believed to exist a threeheaded dog named, Cerberus. It was a monster with a dragon for a tail. It plays the role of guarding the 'Gates to Hades', the kingdom of the dead situated in the under-world.

The 'Hero Myth Cycle' then moves to the realm of "Helpers". And obviously it is evident that Hermione and Ron wholeheartedly acted their roles as 'The Helpers'. These Helpers provide Harry to enlarge his calibre as a wizard whenever the Trio set off for the uncanniness. And thereby satisfying the next realm of the Cycle, 'Growth new skills'.

The next and the crucial stage of the 'Cycle', that is to say, 'Death-rebirth' stage is emphasised in Philosopher's stone, when the young Harry encounter and fights back with Voldemort, who in this volume is embodied on Prof. Quirrel as a mere parasite. Harry faces breath-taking and death-defying fight with them and eventually won single victory.

. The 'call to adventure' in the fourth sequel, The Goblet of Fire, could be traced out, when Harry's name was also seen in one of the parchments in the Goblet. And in the following sequel, The Order of the Phoenix, the realm of 'call to adventure' could be valued, where, Harry, Ron and Hermione set off for a new defence group or army called Dumbledore's Army, a mighty weapon against Prof Umbridge, the High inquisitor. And in the next sequel, The Half Blood Prince, the stage of 'call to adventure' is reflective where, Harry encounters the old copy of book owned by The Half Blood Prince. And following this comes the last sequel, The Deathly Hallows with the stage of 'call to adventure' fulfilling with the coming of Scrimgeour along with Dumbledore's will. 
Following 'Call to adventure' stage of the first step, that is, 'Separation' or 'Departure', the following comes the stage of 'Initiation'. The Initiation, much like the departure is broken into steps. The first comes 'the road of trials'. This can be seen as a series of hoops the hero should jump through, so as to win his goal. Aeneas had to survive the storm of the sea, travel with his men through strange lands, and performs battles in the Aeneid (Damrosch, Alliston, and Brown 121). In the Goblet of fire, the thing to which we get more enchanted was, precisely the 'Triwizard Tournament', and obviously it is the same thing which offers us the stage of 'the road of trials' too. This very task get the more bizarre air, when are introduced to 'Dragons' in this task. Another clue for our quest for myth gets satisfied here since 'dragons' have always been associated with mythologies. And following it there comes another one in the very last sequel, Deathly Hallows, a 'Ukrainian' of 'Gringgotts Bank'. Following the first task, there is the second task entrusted to the candidates, survive underwater for an hour. And here we are also welcomed by another surprise, 'Merpeople'! Luckily, they are too annexed dates back too myths.

As in the fourth series, 'the road of trials', act the same in the fifth series, Order of phoenix, with its slight variation of risk. Here, Harry had to overcome the task of finding the 'The Prophecy' revealing the affinity between him and Voldemort. As moving to the next sequel, The Half Blood Prince, 'the road of trial' is satisfied in the twenty sixth chapter titled 'The Cave'. Where Harry had to accompany with Dumbledore to seize one the 'Horror' moulded out by Voldemort to entrust himself immortal. And this very stage of 'the road of trial', however make the clear cut way to the crucial moulding of the next and last sequel The Deathly Hallows! Here, the 'the road of trial' of the second stage of the 'mono myth cycle' of Campbell, is acutely evident in the arena, where Harry encounters with Voldemort in the chapter 36. Referring through this very scene out of The Deathly Hallows mentioned above, we are once again accidently encountering another unexpected Christian Mythical reference 
in Harry Potter. This notion might serve as a surprise to readers who recount all the schools and churches that banned Harry Potter! As it seems promoting 'witchcraft', but on the contrary Rowling recurrently seems relying on 'Christianity'. This is damn provable in this very last and the seventh sequel of the series, The Deathly Hallows! Along with this religious mythical allusion, one such another religious allusion we could sort out from the very series is 'Nagini'. From the very beginning of the series itself we are familiar with the very Creature 'Nagini'. Along with mythical characteristics, Nagini appears as a crucial mate for Voldemort, as it serves the function of one of the Horcrux created by he himself. Legends assert that, Nagas live in an underground city and have impressive magical powers. Female nagas, irrespective of legends, are named as Nagini!

The next is the last realm of the second stage of the 'cycle' (Initiation), that is, "Supernatural Aid"! Here, to emphasise this stage of the cycle, it is more useful relaying on the very last sequel, The Deathly Hallows. In this series we are introduced a scene in the thirty fourth chapter, where it could easily be answered. This same kind of 'supernatural aid' seems evident in the Goblet of Fire too, at the episode, where Voldemort attempts to murder Harry and the duel of both following, here one could trace out the omnipotent presence of Lilly, James and Cedric.

Focusing on the scene, where Voldemort is attacking the hero, Harry, in chapter 32 of the series, titled, 'Flesh, Blood, and Bone', Voldemort resurrect out of lack ness to a human figure. And what it matters for us is the, 'Restoration Potion' he made. This very idea of the Restoration potion has its root in the Roman mythology.

Back to Campbell's cycle, one could figure out the role of Woman as Goddesses. In ancient myths like Aeneid, the hero meets the goddesses. In modern time, the stories represents some other feminine characters important to the hero. Here, one can stick some female figures as enacting the role of Goddesses for Harry. Obviously there should be 
Minerva McGonagall, MrsWeasly and maybe Hermione too, her role is more applicable as 'Helper or The best friend' archetype, but still, most often she satisfies as something priceless in Harry's life.

And thus now have reached the threshold of the last prior step of the 'hero cycle' of Campbell. It is the "Return". The return is when the hero has completed his journey and has to return to his life. The very final realm is satisfied with 'Crossing the return threshold', 'master of two worlds' and the 'freedom to live'.Taking into account the worth of the Deathly Hallows, one can undoubtedly prove the return arena in the life of Harry, as this series can also be compartmentalised as the very last realm of Harry's life journey. Here, the return is transcended where, Harry decides to come back to life, and to be a helping hand to all the cursed ones. We encounter him after his 'return' to life again to the painful reality of human life and resurrect himself as the single handed Saviour of the cursed beings (here, the Hogwarts members). Along with this stage of Harry's mythical exploration, he naturally fulfilled the step of 'crossing the threshold', 'master of two worlds' and finally 'freedom to live'.

So, through all these interesting analysis and studies, we could value out the unprecedented judging of the hero Harry as an ever-lasting mythical legenderic hero once more, by a precise and quintessential reading of the main theme of the plot, that is to say; the epic war between good and evil, in fact, between Harry and Lord Voldemort. Harry is attributed by the qualities of divine heroes: 'brave at heart', and that's why he was unrefutedly opted for the house of Gryffindor, "Gryffindor, where dwell the brave at heart!' Like my dad" (Deathly Hallows 760). Another mythical heroic attribution all around the world is the unquenchable thirst for adventure, Harry in chapter twenty two of the Deathly Hallows shows testimony to this. He was obsessed and intoxicated with the quest of finding the deathly hallows, and dangerously long for it, "Harry, this isn't a game, this isn't practise! 
Dumbledore left you very clear instructions... forget the deathly hallows, we can't afford to get side-tracked..." (Deathly Hallows489).

While all these add colours to the hero myth qualities of Harry, there is Lord Voldemort, 'Archetypal or mythical foe or evil' force. As in the case of Harry, Rowling did same in the case of Voldemort! He also embodies the attributions of an 'a mythical devil'. The general qualities emphasized on 'devil archetypes' are, 'forces within and outside of us of war against the power of positive life and change, enormous opposition to the very experiences or insights that would lead to healing'. Moving to the mythical characteristics Voldemort shares in Harry Potter. Voldemort is the main antagonist and archenemy in the series, he is such a bizarre nightmare that no one dares call him by his name, instead using phrases like, "You-Know-who', "He-Who-Must-not-Be-Named”, "The Dark Lord” etc. “...'we know the snake's not in Albania, it's usually with Vol-'. "Didn’t I ask you to stop saying that?"...'I'm telling you, if there was one place vol-'. Oi" (Deathly Hallows 325-326). So, in summing up this research paper, one is capable enough of asserting and welcoming the fact that Rowling took myriads of amazing mythical or legenderic characteristics from all around the world. It is not that surprising that the world of Harry Potter is ever memorable and ardently admirable as it mirrors the actual world itself, since the myth always presses the real world of humanity, and Harry himself embodies as "A Modern Mythical Hero". 


\section{Bibliography}

“Archetype.” New World Encyclopaedia. 18 Nov. 2017. <http://www. new world encyclopedia.org/entry/Archetype?oldid=794272>

Abrams, M H and Geoffrey Galt Harpham. A Glossary of Literary Terms. Cengage Learning, 2015.

Campbell, Joseph, and Phil Cousinaeu. The Hero's Journey: Joseph Campbell on His Life and Work. New World Library, 2014.

Campbell, Joseph, et al. The Power of Myth. Turtleback Books, 2012.

---. The Hero with a Thousand Faces. Princeton University.

---. The Power of Myth New York: Doubleday, 1988.

Davidson, Hilda Ellis. “Northern Europe.” World Mythology: The Illustrated Guide. Ed. Roy Willis. London: Duncan Baird Publishers, 1993.191-92.

Davis, B M. The Archetypal Hero in Literature, Religion, Movies, and Popular Culture.1997. Nov 27, $2017<$ http://www.tatsbox.com/hero>

Egan, Jennifer. Visit from the Goon Squad. Windsor. 2012.

Frye, Northrop. "Theory of Archetypes." 28 Oct.

2017.<http://edweb.tusd.k12.az.us/dherring/ap/consider/frye/indexfryeov.htm>

Frye, Northrop. Anatomy of Criticism: Four Essays. New Jersey: Princeton University Press, 1957.

Nagarajan, M S English Literary Criticism and Theory: an Introductory History. Orient Longman, 2006. Press, 2004.Print. 